\title{
HEC-HMS HYDROLOGICAL MODELLING FOR RUNOFF ESTIMATION IN CAMERON HIGHLANDS, MALAYSIA
}

\author{
Laith Abdulsattar Jabbar ${ }^{1}$, Ibrahim Abdulrazak Khalil ${ }^{*}$ and Lariyah Mohd Sidek ${ }^{2}$ \\ ${ }^{1}$ National Center for Water Resources Management, Ministry of Water Resources, \\ Baghdad, Iraq \\ ${ }^{2}$ Department of Civil Engineering, University Tenaga National, Kajang, 43000, \\ Selangor, Malaysia \\ *Corresponding Author
}

\begin{abstract}
In water resources and more specifically in hydrology, the application of mathematical models to represent the hydrological cycle process is crucial. This is the reason why the hydrological concepts are expressed in mathematical language to represent the corresponding behavior observed in the nature. The current research targeted to develop a hydrological model using HEC-HMS model version 4.7.1 for runoff estimation in Cameron Highlands, Pahang, Malaysia. The Geographic Information System (GIS) was utilized to identify the geometric and hydrologist parameters. The Soil Conservation Service-Curve Number (SCS-CN) Method was adopted to estimate the rainfall losses while the Soil Conservation Service-Curve Number (SCSCN) Method was used to transform the excess rainfall into a direct runoff hydrograph. Muskingum Model was adopted for routing the total runoff from the outlet of the sub-basin to the outlet of the total basin. Model calibration was achieved using different sets of data (CN, Lag time and Muskingum K) in which the data used was for seven years (2000 to 2007). Results of model calibration showed very good fit between the simulated and observed data based on Coefficient of determination $\left(R^{2}\right)=0.9$, Nashsutcliffe Efficiency $=0.92$, Root Mean Square Error $=0.1$ and the Percent Bias $=$ $0.77 \%$. The model validation was accomplished based on data for couple of years (2007 to 2009) and it is indicated there is a very good matching between the simulated and observed hydrograph. Eventually, based on what have been presented earlier, it can be concluded that the model can be utilized for the Cameron Highland Watershed.
\end{abstract}

Keywords: ArcGIS, HEC-HMS, Modelling, Rainfall, Runoff

Cite this Article: Laith Abdulsattar Jabbar, Ibrahim Abdulrazak Khalil and Lariyah Mohd Sidek. HEC-HMS Hydrological Modelling for Runoff Estimation in Cameron Highlands, Malaysia. International Journal of Civil Engineering and Technology (IJCIET). 12(9), 2021. pp. 40-51.

https://iaeme.com/Home/issue/IJCIET?Volume $=12 \&$ Issue $=9$ 


\section{INTRODUCTION}

Malaysia is a humid tropical country where the rainfall is abundant and contributes to an average of 2000-4000 $\mathrm{mm}$ a year. The annual average precipitation may exceed the above range with the exception of extreme events which results in many times of flooding for several areas are during the monsoon periods [1]. For the period from November to March, seasonal floods usually occur during the North-East Monsoon season while Southwest Monsoon occur from May to September. The two inter-monsoon period, in April and October are normally interested by variable wind and thunderstorm in the afternoon [2]. The heavy rainfall and the high concentration of runoff are the main reasons that cause flood in Malaysia. Population growth, climate change and socio-economic development can be considered the affective factors that leads to additional flood frequencies. Based on that, it is essential to adopt a policy to assess the flood discharge [3]. Since the measurement of all parameters affect the runoff is crucial, there is a need to choose the appropriate model with minimum input data requirements, simple structure, and realistic accuracy [4]. HEC-HMS Model is a hydrological model that match the mentioned criteria and has been developed by the Hydrologic Engineering Center of the US Army Crops of Engineers [5] and extensively adopted in various researches [6, 7, 8]. HECHMS is a mathematical model for watershed representation which involves various approaches for simulating the response of runoff of a catchment by demonstrating the catchment with communicated hydrologic and hydraulic components. The basin model composes of three main models; the loss, the transform and the base flow. Each element in the model fulfils various roles of the precipitation-runoff process within a part of the catchment known as a sub-basin. The main result of modelling is the computation of stream flow hydrographs at the catchment outlet [9].

Reference [9] applied the HEC-HMS model for flood forecasting in Wan'an Catchments in China in which the model has been calibrated and verified using the collected data and the errors in peak discharges were within the allowable limits. Reference [10] developed HECHMS Model in watershed of wadi Cheliff-Ghrib, Algeria in order to forecast the response of the basin to the impact of climate changes scenarios and land use and it is concluded that with extreme rain storms, the power of land use reduces. Reference [10] was estimated the flood for Wadi Ressoul Watershed, Algeria using HEC-HMS Model relying on several events. Results of Model validation showed very high correlation between the observed and simulated values. Another study performed by Reference [12] which utilized the hydrological model (HEC-HMS) for modelling the rainfall-runoff in Shipra basin, India in which it shows a very good results after the calibration.

There are many other studies which adopted the HEC-HMS model for flood forecasting in many countries $[13,14,15,16,17,18,19,20,21,22]$ in which the model proved it's accurate results in terms of basin response in time and space at event scale and for a long and continuous period as well as simulating different scenarios in forecasting the flood and the early detection. The objective of the current study is to simulate the rainfall-runoff process by using the hydrological model of HEC-HMS in the catchment of Putrajaya, Selangor, Malaysia.

\section{METHODOLOGY}

The methodology adopted in the current study can be divided into five main tasks as illustrated into Fig. 1 below: (1) Identifying the study area; (2) data collection and DEM processing, delineating streams and watershed characteristics, terrain processing and basin processing; (3) Model development; (4) model calibration and validation and (5) Final Hydrograph Development. 


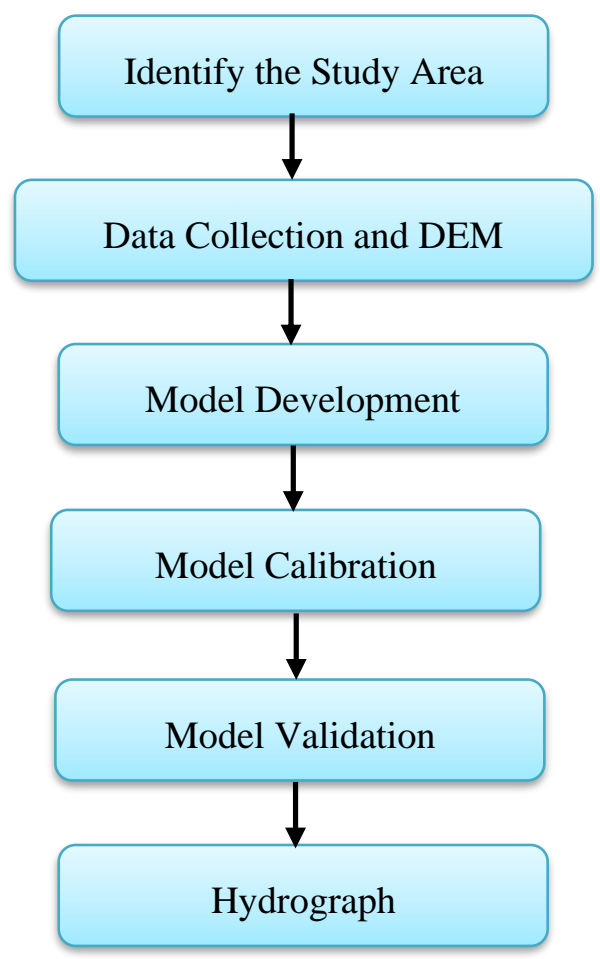

Figure 1 Methods adopted in the current research.

\subsection{Study Area}

Cameron Highlands $(\mathrm{CH})$ is a district in Pahang, Malaysia. To the north, its boundary touches that of Kelantan; to the west it shares part of its border with Perak and situated at the northern western tip of Pahang and is located around $200 \mathrm{Km}$ from the Capital Kuala Lumpur. Malaysia is a tropical country and hence the climate of $\mathrm{CH}$ ranges between a tropical rainforest climate and a subtropical highland climate in which the annual rainfall is higher than $2700 \mathrm{~mm}$ and the mean annual temperature is $18^{\circ} \mathrm{C}$. Fig. 2 illustrates the location map of Cameron highlands.

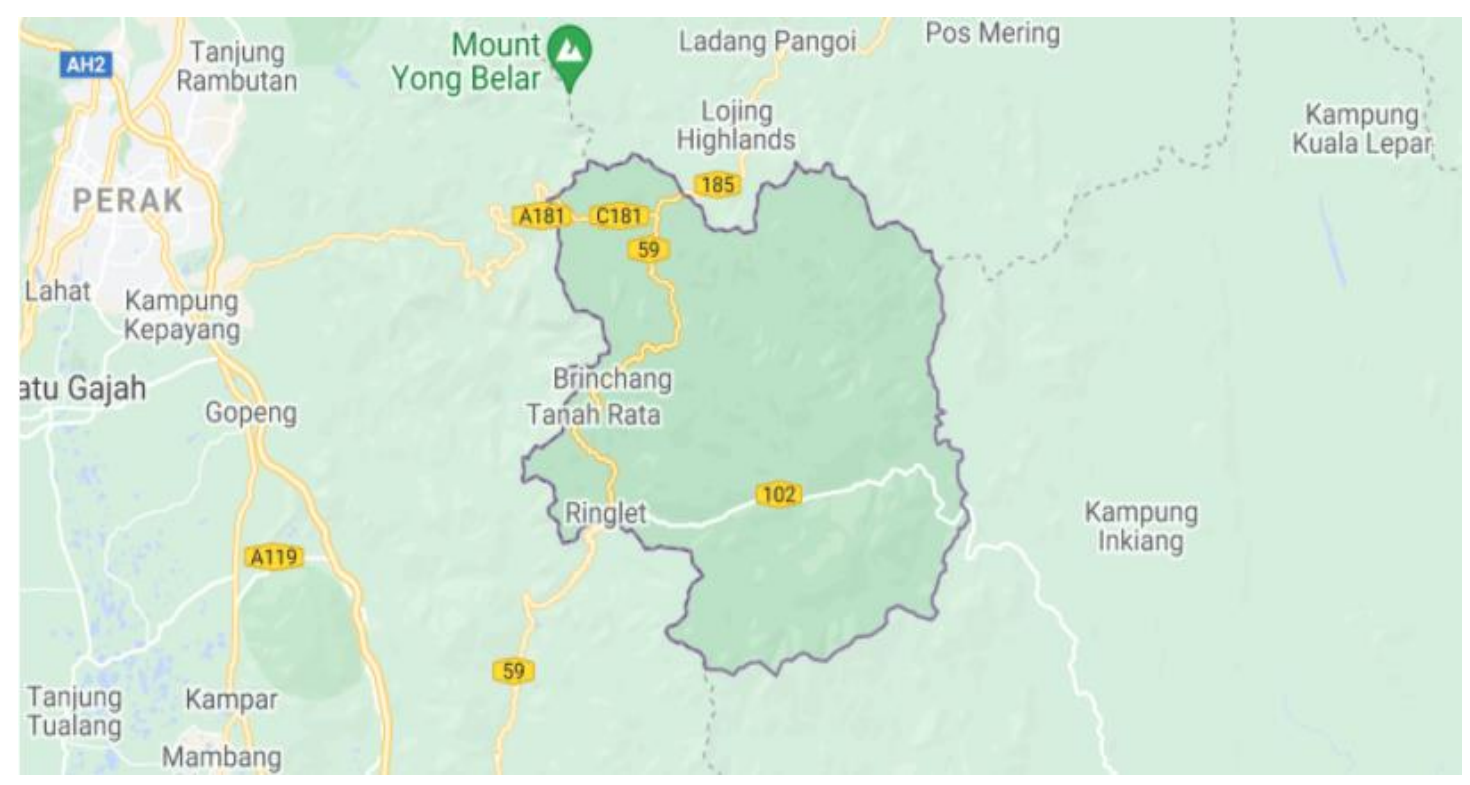

Figure 2 Location map of Cameron Highlands 


\subsection{Data Collection and Digital Elevation Model}

Data collection is the most dauting task in any hydrological simulation. The first set of data that need to be collected is the Digital Elevation Model (DEM) of the study area in which its function is essential and fundamental in physical characterization and calculation of the parameters. Hence, in the current study, the researchers were used a 30" x 30" resolution DEM maps for the study area that are generated from data provided by the United States Geological Survey (USGS) as shown in Fig. 3 below.
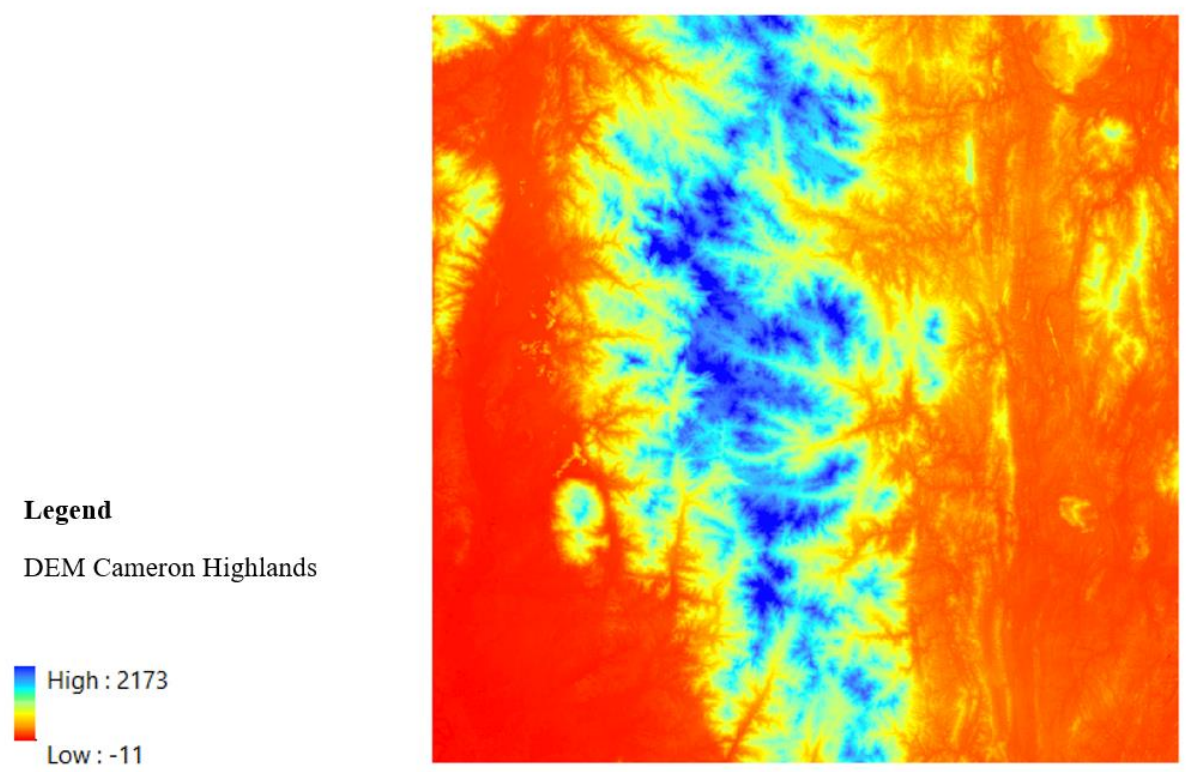

Figure 3 Digital Elevation Model (DEM) map of Cameron Highlands Watershed.

Meteorological data also play a significant role in the simulation since it gives an indication for the rainfall depth within the simulation period which directly affect the amount of runoff generated. The rainfall data have been collected from Global weather data for SWAT which have been downloaded for the period of fourteen years (i.e. 2000 to 2014). Regarding the soil type, it has been collected from FAO using the website: http://soilgrids.org/.

\subsection{HEC-HMS Hydrological Modelling}

HEC-HMS is hydrologic modeling software developed by the US Army Corps of EngineersHydrologic Engineering Center [23]. It is designed to simulate the rainfall-runoff processes in an extensive range of geographic areas such as flooding, water supply, large river basin to small urban and natural watershed runoff. For building the rainfall-runoff model of the $\mathrm{CH}$ watershed, version 4.7.1 of HEC-HMS was used in the current research. Development of the basin model which includes the basin model is the first step to be considered in the simulation in which the hydrological elements need to be inserted either by manual input (connecting elements into dendritic network) or by using HEC-GEOHMS with DEM in ArcGIS. In the current study and with the new features of 4.7.1 version, the basin model was developed and delineated using the GIS tool in HEC-HMS Model. There are twenty-five (25) sub-basins within the study area which have been adopted as illustrated in Fig. 4. 


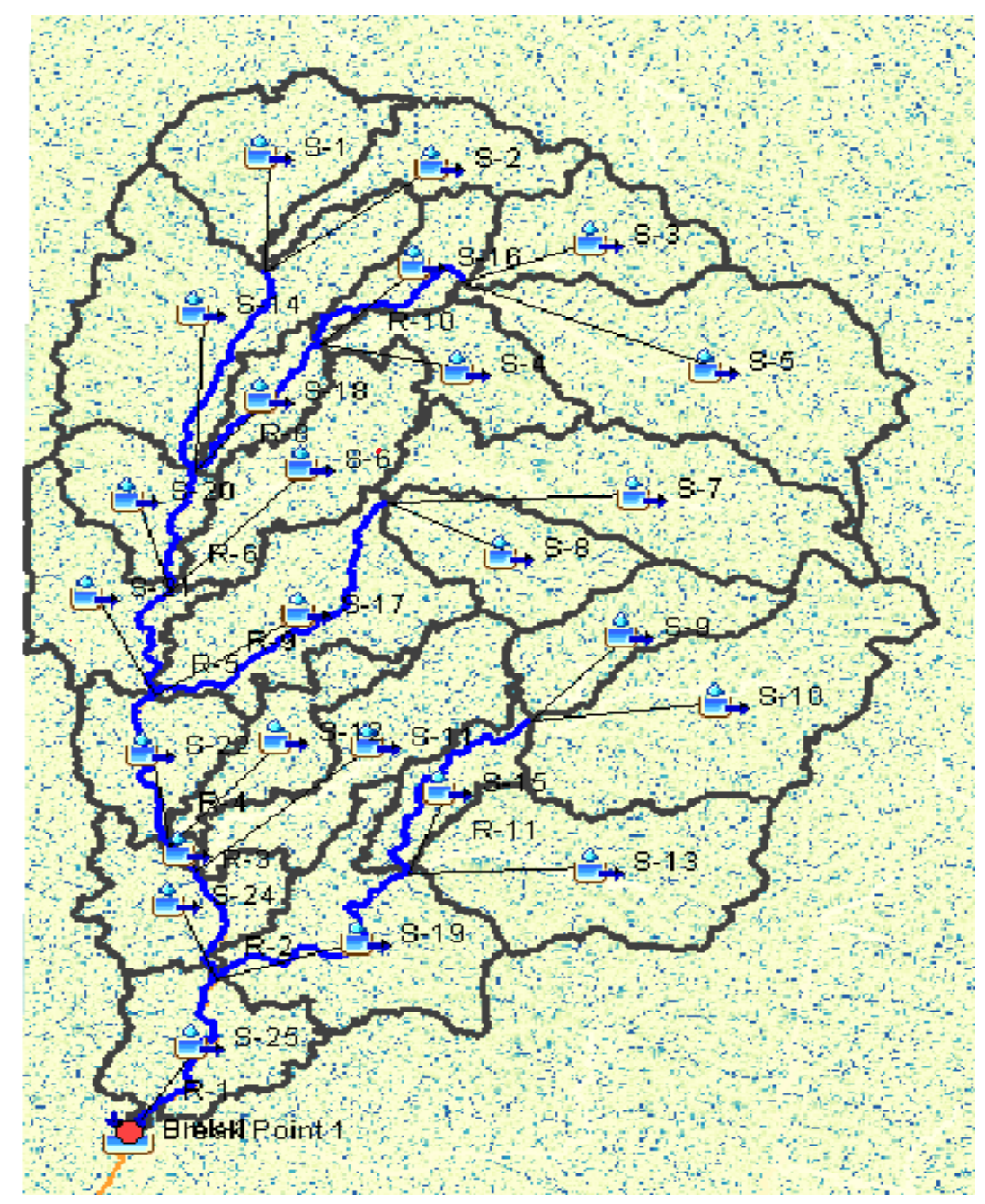

Figure 4 Overall sub-basins within the study area

\subsubsection{Selection of Modelling Methods and Parameters}

The Modeling methods for all sub-basins are unified (i.e. the Loss Model and Transform Model adopted the same methods for all the subbasins). The following paragraphs describes the Loss and Transform Models in more details.

\subsubsection{Loss Model}

This model is used for assessing the runoff via determining the total losses from the total precipitation. The loss method adopted in the current research is the Soil Conservation Service (SCS) Curve Number. This method necessitates the prediction of curve number, initial abstraction and the imperviousness percent for each sub-basin. Curve number is the function of soil type, land use and antecedent moisture condition. For this purpose, the international map of land cover has been utilized in order to get the relevant factors which have been obtained from the European Space Agency.

Depending on International Food and Agriculture Organization (FAO) with a scale of 1: 500000 , soil data has been obtained in order to be further analyzed and identify their types as presented in Fig. 5. 

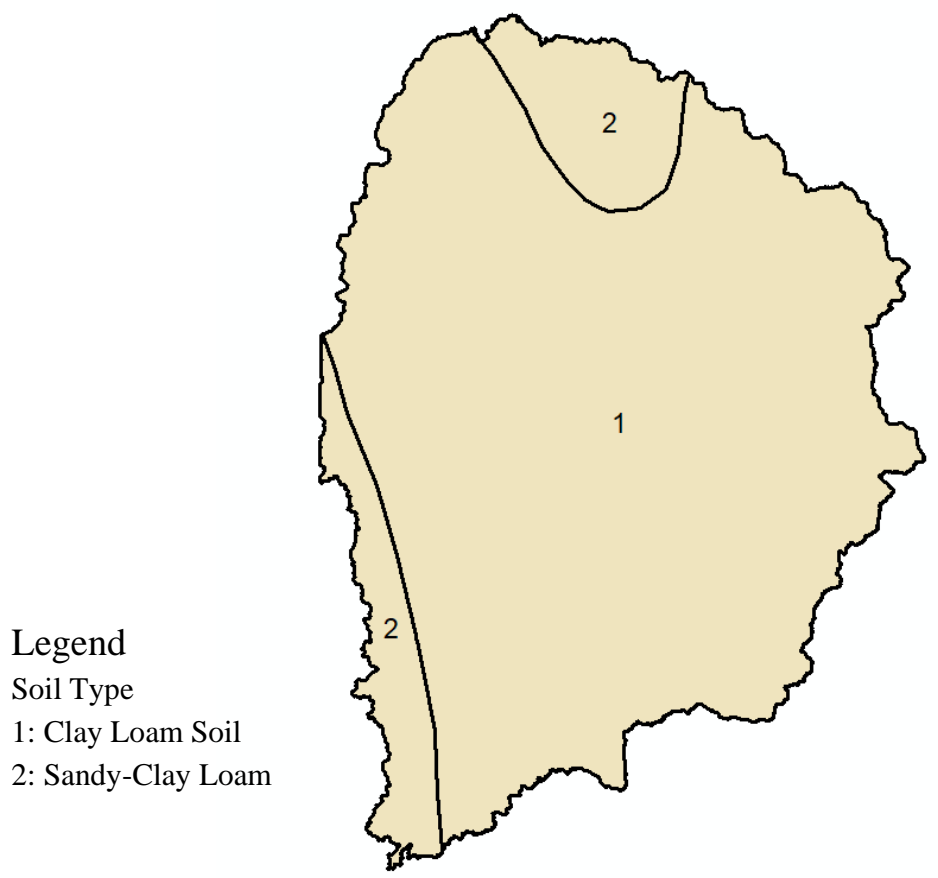

Figure 5 Soil type distribution within the study area according to FAO

One of the most important parameters that need to be considered in the Loss Method is the Initial Abstraction (Ia) is a parameter that accounts for all losses prior to the occurrence of runoff and consists mainly of interception, infiltration, evaporation and surface depression storage. In theory, all rainfall minus Initial Abstraction will generate the runoff from a specified catchment. From the analysis of results from many small experimental watersheds, the SCS developed an empirical relationship of Ia [24]. This value is estimated as the function of the curve number as illustrated in Equation 1 below.

$$
\text { Ia }=0.2 * \frac{25400-254 * C N}{\mathrm{CN}} \text { (SI Units) }
$$

Where,

\section{Ia: Initial Abstraction (mm)}

CN: Curve Number; ranges from 100 (water bodies) to approximately 30 for permeable soils.

Another parameter that need to be estimated in LOSS Method is the percent imperviousness which is the percent of basin surface that is impervious and directly connected to the stream flow. In the current research and due to the difficulty to determine precisely this value, it is related to the percent of built-up. Thus, the percent of built-up in each sub-basin is considered as percent impervious.

\subsubsection{Transform Model}

It is also called Direct Runoff Model as it transforms the excess precipitation into direct runoff hydrograph. In the present study, the Soil Conservation Service (SCS) Unit Hydrograph Model is adopted and applied. This method requires the estimation of lag time $\left(\mathrm{T}_{\text {lag }}\right)$ which is defined as the time from the centroid of rainfall excess to the centroid of direct runoff [24]. The lag time can be estimated based on Equation 2 which is the only required input data for each basin within this model. Based on Equation 2, it is required to estimate the Time of Concentration (Tc) which can be predicted using Bransby-Williams Equation (Equation 3).

$$
\mathrm{T}_{\text {Lag }}=0.6 \mathrm{Tc}
$$




$$
\mathrm{Tc}=\frac{0.0885 \mathrm{~L}}{\mathrm{~S}_{0}^{0.2} \mathrm{~A}_{0}^{0.1}}
$$

Where,

Tc: Time of Concentration (hours)

Ao: Drainage area (sq. miles); and

So: Channel Slope $(\%)$.

The units of area were changed into sq. miles in order to estimate the time of concentration in the units of hours.

\subsubsection{Routing Model}

Flood routing is a technique of determining the flood hydrograph at the downstream of the river by utilizing the inflow data of upstream. The routing of the total runoff from the outlet of the sub-basins to the outlet of the entire basin was accomplished by adopting the Muskingum Model. In this method, the parameters $\mathrm{X}$ and $\mathrm{K}$ are required to be evaluated. Theoretically, $\mathrm{K}$ parameter is the time of a passing wave in a reach length and $\mathrm{X}$ parameter is constant coefficient which varies between 0-0.5. Based on some relevant studies [25, 11], X adopted as 0.2. Both of $\mathrm{K}$ and $\mathrm{X}$ can be estimated based on Equations 4 and 5 respectively. Once $\mathrm{K}$ is estimated, $\mathrm{X}$ can be estimated by trial and error.

$$
\mathrm{K}=\frac{L}{V}
$$

Where,

L: length of the reach; and

$\mathrm{V}$ : mean velocity $(\mathrm{m} / \mathrm{s})$.

$$
\mathrm{X}=\frac{I^{1 / 2}}{n p^{2 / 3}}
$$

Where,

I: River slope

$\mathrm{N}$ : Manning roughness coefficient; and

P: Wetted perimeter

\section{RESULTS AND DISCUSSIONS}

The basin model is the most important component in HEC-HMS to simulate the rainfall-runoff process over the entire watershed. To develop the $\mathrm{CH}$ basin model, 25 sub-basins and 12 reaches were delineated using the GIS tool in HEC-HMS. There are three models were considered for the sub-basins and reaches which includes the Loss Model, Transform Model and Routing Model. Each of these models has its own data input requirements.

\subsection{Model Calibration}

Model calibration is an important part in modeling in order to give a reliable output in which the successful application of hydrologic watershed model depends upon how well the model is calibrated. The calibration is the process of optimizing the model parameters to get the good goodness of fit between the simulated and observed hydrographs. Fig. 6 illustrates the process of calibration in HEC-HMS [24]. 


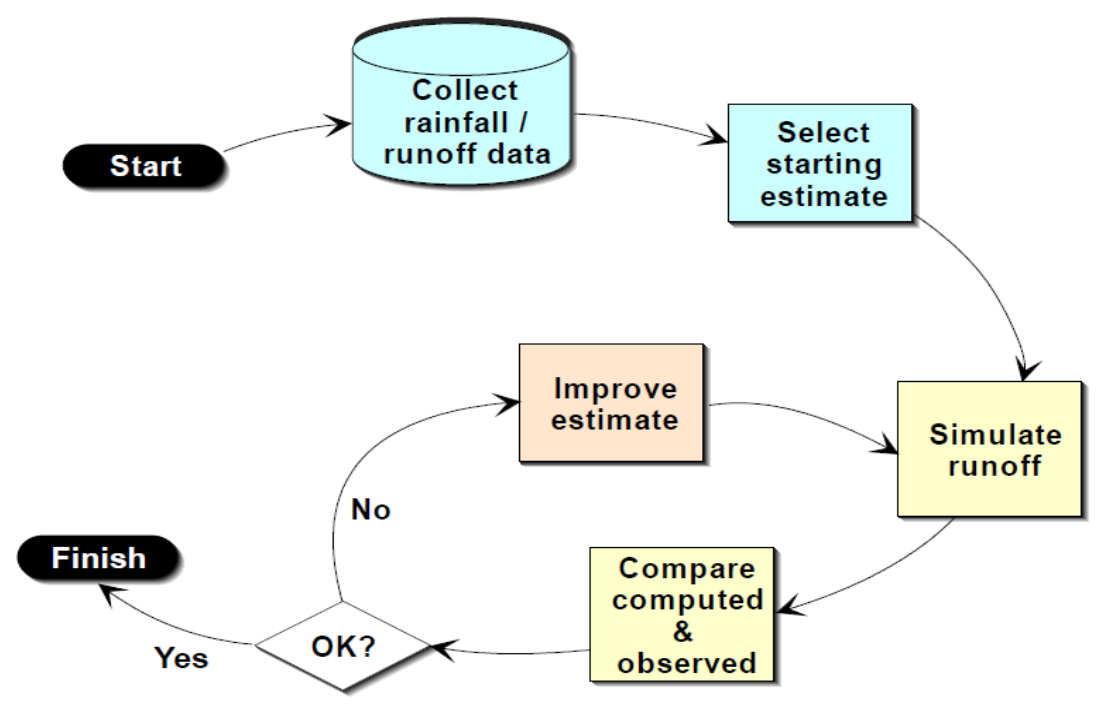

Figure 6 Calibration process in HEC-HMS (Source: [24])

In the current research, the model calibration was done by using the estimated parameters to achieve a good fitness between simulated and observed data. The auto-calibration (through optimization trials) available in the HEC-HMS model was used for optimizing the model parameters (i.e. from 2000 to 2007). Half of the data available was used for the calibration and in the presence of these data, optimization of the parameters was done using a systematic search procedure that yields the best fit between the observed and computed runoff. A variety of objective functions are provided in HEC-HMS to measure the goodness of the fit between the simulated and observed runoff in different ways such as peak weighted RMS error, percent error peak, percent error volume, sum absolute residuals, sum squared residuals, and time weighted error. These objective functions were recognized one by one and the objective function that gives the better result, indicated the end of calibration. Table 1 presents the estimated and calibrated Model parameter for each sub-basin in which these parameter values are selected based on the calibration parameter constrains [24].

Table 1 Estimated and Calibrated Model Parameter for CH sub-basins

\begin{tabular}{|c|c|c|c|c|}
\hline \multirow{2}{*}{ Sub-Basins } & \multicolumn{2}{|c|}{ Curve Number } & \multicolumn{2}{c|}{ Lag Time } \\
\cline { 2 - 5 } & Estimated & Calibrated & Estimated & Calibrated \\
\hline S-5 & 73 & 77.6 & 1.26 & 1.30 \\
\hline S-3 & 73 & 73 & 0.77 & 0.77 \\
\hline S-1 & 77 & 77 & 0.97 & 0.98 \\
\hline S-4 & 83 & 81.3 & 1.02 & 1.02 \\
\hline S-16 & 77 & 77 & 0.96 & 0.96 \\
\hline S-2 & 80 & 80 & 1.27 & 1.27 \\
\hline S-14 & 84 & 84 & 1.24 & 1.24 \\
\hline S-18 & 85 & 84 & 0.92 & 0.93 \\
\hline S-6 & 73 & 80 & 1.42 & 1.32 \\
\hline S-20 & 77 & 77 & 0.94 & 2.14 \\
\hline S-7 & 77 & 77 & 1.48 & 1.48 \\
\hline S-8 & 77 & 77 & 0.80 & 1.56 \\
\hline S-17 & 84 & 81.8 & 1.20 & 1.20 \\
\hline S-21 & 77 & 77 & 1.26 & 1.34 \\
\hline S-22 & 77 & 77 & 1.08 & 1.93 \\
\hline S-12 & 83 & 99 & 1.54 & 1.72 \\
\hline
\end{tabular}




\begin{tabular}{|c|c|c|c|c|}
\hline S-11 & 80 & 89 & 1.75 & 2.74 \\
\hline S-23 & 83 & 83 & 0.29 & 0.54 \\
\hline S-10 & 83 & 83 & 1.15 & 0.89 \\
\hline S-9 & 83 & 83 & 0.91 & 1.20 \\
\hline S-13 & 77 & 69.98 & 1.07 & 1.07 \\
\hline S-15 & 77 & 78.1 & 1.02 & 1.23 \\
\hline S-19 & 77 & 77 & 1.19 & 0.98 \\
\hline S-24 & 80 & 80.5 & 1.10 & 1.20 \\
\hline S-25 & 77 & 69.2 & 1.13 & 1.14 \\
\hline
\end{tabular}

Table 2 presents the estimated and calibrated Model parameter for the 12 reaches and Table 3 presents the results of evaluation parameters during calibration which includes the Coefficient of Determination, Nash-sutcliffe Efficiency, Root Mean Square Error and Mean Absolute Error for the reaches. Based on the calibration parameters presented in Tables 2 and 3, the simulated and observed peak discharge values and volume for the entire watershed are illustrated in Table 4 .

Table 2 Original and calibrated values of Muskingum K parameter

\begin{tabular}{|c|c|c|}
\hline \multirow{2}{*}{ Channel ID } & \multicolumn{2}{|c|}{ Muskingum K Factor } \\
\cline { 2 - 3 } & Original Value & Calibrated Value \\
\hline R-10 & 1.85 & 1.89 \\
\hline R-8 & 1.9 & 1.94 \\
\hline R-12 & 0.67 & 0.68 \\
\hline R-6 & 0.19 & 0.04 \\
\hline R-5 & 1.65 & 12.59 \\
\hline R-9 & 1.02 & 1.04 \\
\hline R-4 & 0.13 & 0.2 \\
\hline R-3 & 0.22 & 0.06 \\
\hline R-2 & 0.33 & 0.5 \\
\hline R-11 & 0.5 & 0.76 \\
\hline R-7 & 2.39 & 2.45 \\
\hline R-1 & 2.44 & 0.48 \\
\hline
\end{tabular}

Table 3 Values of evaluation parameters during calibration for the reaches

\begin{tabular}{|l|c|}
\hline \multicolumn{1}{|c|}{ Measure } & Value \\
\hline Coefficient of Determination $\left(\mathrm{R}^{2}\right)$ & 0.90 \\
\hline Nash-sutcliffe Efficiency (NSE) & 0.92 \\
\hline Root Mean Square Error (RMSE) & 0.1 \\
\hline Percent Bias & $0.77 \%$ \\
\hline
\end{tabular}

Table 4 Simulated and Observed values of peak discharge and volume for the entire watershed

\begin{tabular}{|l|c|c|}
\hline & Simulated Value & Observed Value \\
\hline Volume $\left(1000 \mathrm{~m}^{3}\right)$ & 59057614.1 & 58232917.4 \\
\hline Peak Discharge $\left(\mathrm{m}^{3} / \mathrm{s}\right)$ & 2611.2 & 2600 \\
\hline
\end{tabular}

The final results of hydrological modelling displayed a very good fit between the simulated and observed hydrographs as depicted in Fig. 7 in which it shows the time series comparison between the simulated and observed discharges for the outlet of the entire watershed for the calibration period (2000-2007). 
HEC-HMS Hydrological Modelling for Runoff Estimation in Cameron Highlands, Malaysia

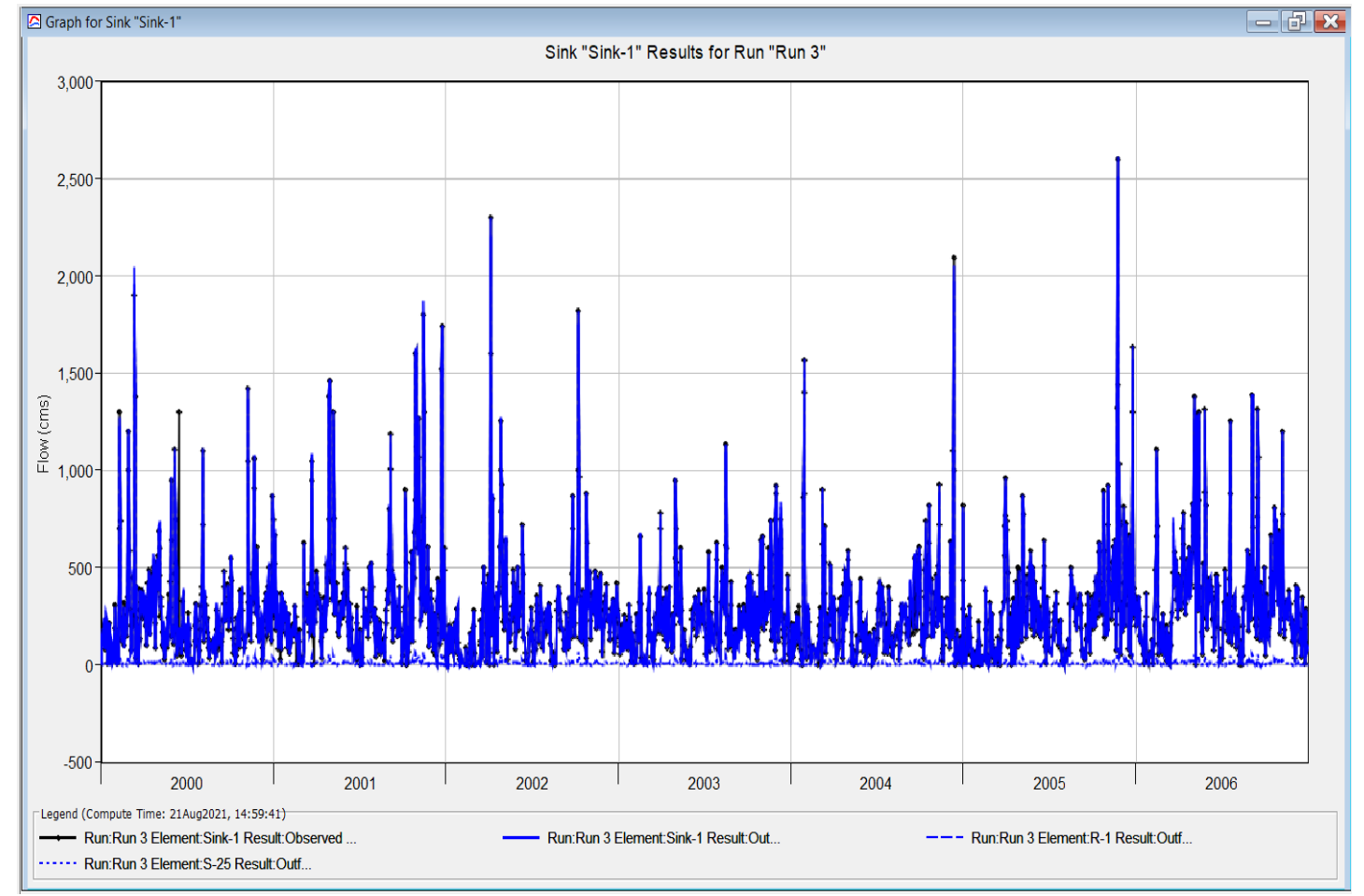

Figure 7 Comparison of the simulated and observed hydrograph after calibration

\subsection{Model Validation}

For validating the model, data from couple of years (i.e. 2007 to 2009) were used in which the parameters obtained during the calibration was used for validation. The peaks of the simulated and observed hydrographs are depicted in Fig. 8.

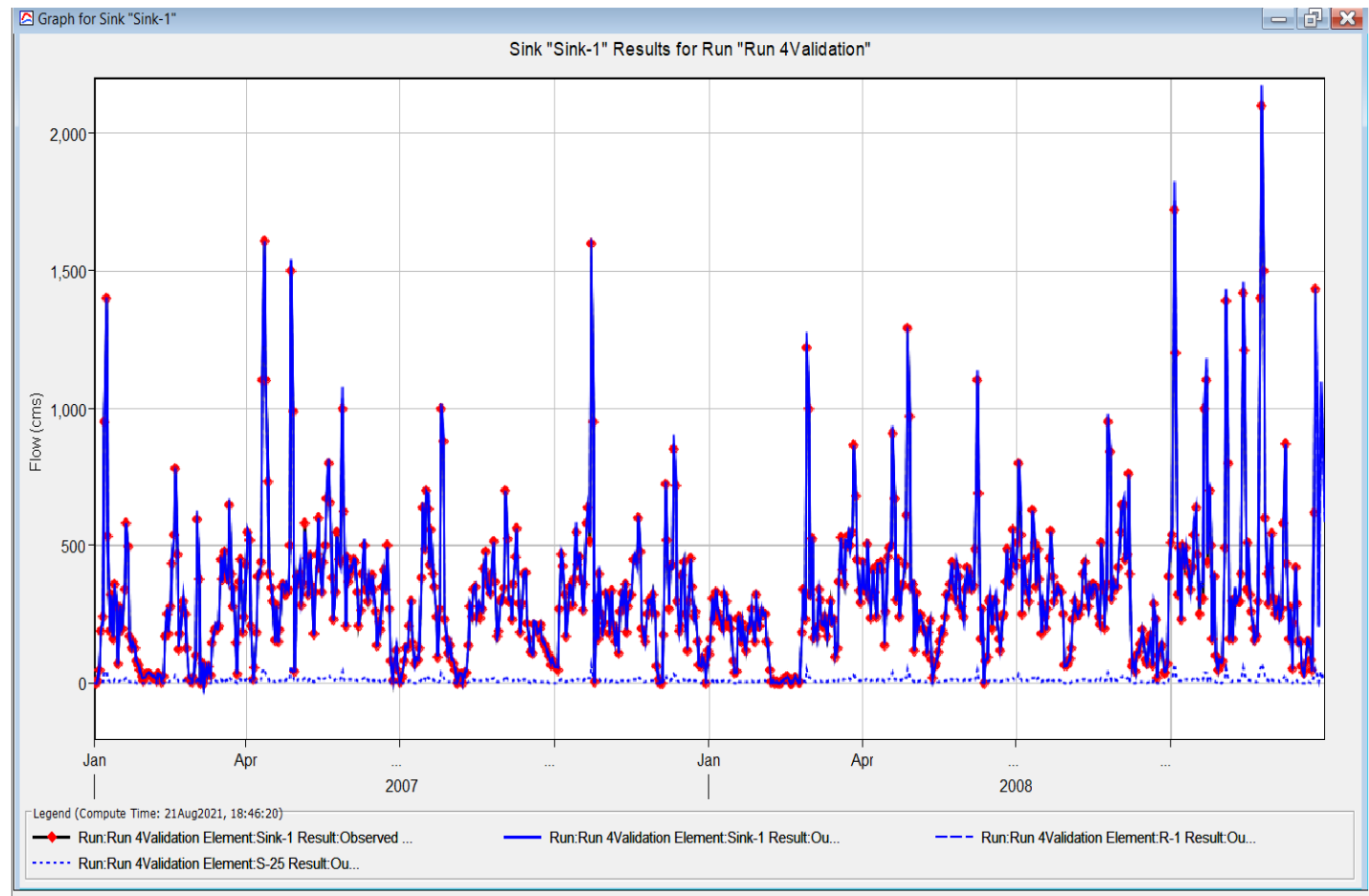

Figure 8 Comparison of the simulated and observed hydrograph after validation 


\section{CONCLUSIONS}

The current research targeted to predict the peak runoff from Cameron Highland watershed by examining the efficiency of HEC-HMS when applied to this case. The generated model was run repeatedly and for many times in which the modeled discharge values were compared with the monitored values. In this respect, the curve number, lag time and Muskingum K parameters were calibrated for seven years (2000-2007) and validated for couple of years (2007 to 2009). Results of computing approved the results of the model and revealed that simulated and observed discharges are close to each other. Furthermore, the model calibration showed very good fit between the simulated and observed data based on Coefficient of determination $\left(\mathrm{R}^{2}\right)=$ 0.90, Nash-sutcliffe Efficiency $=0.92$, Root Mean Square Error $=0.1$ and the Percent Bias $=$ $0.77 \%$. Thus, the model can be applied in the Cameron Highland Watershed.

\section{ACKNOWLEDGMENT}

The authors would like to express their gratitude to the National Center for Water Resources Management and to the University Tenaga Nasional for supporting this research.

\section{REFERENCES}

[1] Suhaila, J. and A.A. Jemain, 2007. Fitting daily rainfall amount in Malaysia using the normal tansform distribution. J. Applied Sci., 7, PP. 1880-1886.

[2] Lawal, B. S. Mansor and A. R. Mahmud. 2004. Spatial information technology in flood early warning system: An overview of theory, application and latest developments in Malaysia. $J$. Disaster Prevention Manage, 13, PP. 356-363.

[3] Bosamiya, B., Gandhi, H., M. 2018. Hydrological Modeling using HEC-HMS. International Journal for Research in Applied Science \& Engineering Technology, Vol. 6. ISSN: 2321-9653.

[4] Sharifi, F. Safapoor, Sh. and Ayoobzade, S., 2004, Evalution of AWBM 2002 model in simulation of hydrological processes some of watersheds in Iran, Journal of Research and Constructional, 35-42.

[5] US Army Corps of Engineers. 2016. https://www.usace.army.mil/Media/News-Releases/NewsRelease-Article-View/Article/652845/us-army-corps-of-engineers-releases-work-plan-forfiscal-year-2016-civil-works/. Accessed in May, $18^{\text {th }} 2021$.

[6] Arekhi, S. Rostamizad, G. and Rostami, N., 2011, "Evaluation of HEC-HMS Methods in Surface Runoff Simulation (Case Study: Kan Watershed, Iran)", Advances in Environmental Biology, AENSI, 1316-1321.

[7] Kneble, M. Yang, Z. Hutchison, K. and Maidment, D. R., 2005, Regional scale flood modeling using NEXRAD rainfall, GIS, and HEC-HMS / HEC-RAS: a case study for the san Antonio River Basin Summer 2002 storm event, Journal of environmental management, 75, 4, 325-336.

[8] Garcia, A. Sainz, A. Revilla, J. and Alvarez, C., 2008, Surface water resources assessment in scarcely gauged basins in the north of spain, Journal of Hydrology, 356, 312-326.

[9] Oleyiblo, J. O. and Li, Zhi-jia. 2010. Application of HEC-HMS for flood forecasting in Misai and Wan'an Catchments in China. Water Science and Engineering, 3 (1), PP.14-22.

[10] Mokhtari, E., H., Remini, B., Hamoudi, S., A. 2016. Modelling of the rain-flow by hydrologic modelling software system HEC-HMS watershed's case of wadi Cheliff-Ghrib, Algeria. Journal of Water and Land Development, No. 2, PP. 87-100. ISSN: 1429-7426. 
[11] Skhakhfa, I. D. and Ouerdachi, I. 2016. Hydrological modelling of wadi Ressoul watershed, Algeria, by HEC-HMS model. Journal of Water and Land Development, No. 31, PP. 139-147. DOI: 10.1515/jwld-2016-0045.

[12] Sahu, S., Pyasi, S. K., Galkate, R. V. and Shrivastava, R. N. 2020. Rainfall-Runoff modelling using HEC-HMS model for Shipra River basin in Madhya Pradesh, India. International Journal of Current Microbiology and Applied Sciences., 9 (8), PP. 3440-3449.

[13] Yusop, Z., Chan, C. H. and Katimon, A. 2007. Runoff characteristics and application of HECHMS for modelling stormflow hydrograph in an oil palm catchment. Water Science and Technology, Vol. 56 (8). DOI: 10.2166/wst2007.690.

[14] Lincoln, W. S. 2009. A modeling approach for operational flash flood forecasting for smallscale watersheds in central Iowa. Master Thesis, Iowa State University.

[15] Razi, M. A. M., Ariffin, J., Tahir, W. and Arish, N. A. M. 2010. Flood estimation studies using hydrologic modelling system (HEC-HMS) for Johor River, Malaysia. Journal of Applied Sciences, Vol. 10 (11). ISSN: 1812-5654.

[16] Malek, M. A., Heyrani, M. and Juneng, L. 2013. Stream flow projection for Muar River in Malaysia using Precis-HEC-HMS Model. ASM Sci. J., 9 (1), PP. 8-19.

[17] Halwatura, D. and Najim, M. M. M. 2013. Application of the HEC-HMS model for runoff simulation in a tropical catchment. Environmental Modelling and Software, Vol. 46, PP. 155162.

[18] Gumindoga, W., Rwasoka, D. T., Nhapi, I. and Dube, T. 2017. Ungauged runoff simulation in Upper Manyame Catchment, Zimbabwe: Application of the HEC-HMS Model. Physics and Chiemistry of the Earth, Parts A/B/C, Vol. 100, PP. 371-382.

[19] Romali, N. S., Yusop, Z. and Ismail, A. Z. 2018. Hydrological Modelling using HEC-HMS for flood risk assessment of Segamat Town, Malaysia. IOP Conference: Materials Science and Engineering 318. DOE: 10.1088/1757-899X/318/012029.

[20] Cheah, R., Billa, L., Chan, A., Teo, F. Y., Pradhan, B., Alamri, A. M. 2019. Geospatial modelling of watershed peak flood discharge in Selangor, Malaysia. Water, 11. DOI: $10.3390 /$ w11122490.

[21] Niyazi, B. A., Masoud, M. H., Ahmed, M., Basahi, J. M., Rashed, M. A. 2020. Runoff assessment and modeling in arid regions by integration of watershed and hydrologic models with GIS techniques. Journal of Afrtican Earth Sciences, Vol. 172.

[22] Castro, C.V. and Maidment, D. R. 2020. GIS preprocessing for rapid initialization of HECHMS hydrological basin models using web-based data services. Environmental Modelling \& Software, Vol. 130.

[23] Feldman A. D. (ed.). 2000. Hydrologic modeling system HEC-HMS: Technical Reference Manual. Davies, CA. U.S. Army Crops of Engineers, Hydrologic Engineering Center, PP. 149.

[24] US Army Corps of Engineers. 2000. Hydrologic Modeling System HEC-HMS, Technical Reference Manual. Hydrologic Engineering Center.

[25] Majidi, A. and Shahedi, K. 2012. Simulation of rainfall-runoff process using Green-Ampt Method and HEC-HMS Model (Case study: Abnama Watershed, Iran). International Journal of Hydraulic Engineering, 1(1): 5-9. DOI: 10.5923/j.ijhe.20120101.02. 